Original Research Paper

\title{
The Toxic Spectrum of Ricinus Communisand Zingiber Officinalis Essential Oils against Musca Domestica L.
}

\author{
Hanan Abo El-Kassem Bosly \\ Department of Biology, Faculty of Science, Jazan University, Jazan, Saudia Arabia
}

Article history

Received: 23-07-2017

Revised: $13-11-2017$

Accepted: 2-12-2017

Email: dr_2009_bosly@hotmail.com

\begin{abstract}
The housefly, Musca domestica L., is a cosmopolitan insect, associated with various diseases and is one of the species with the greatest ability to develop resistance to insecticides. The study designed to evaluate the larvicidal, pupicidal, adulticidal and ovicidal effect of lethal concentrations LC50 of $R$. communis and $Z$. officinalis essential oils against the housefly $M$. domestica L. The larvicidal mortality (LC50) values of $R$. communis and Z. officinalis essential oils against $M$. domestica were 349.40 ppm and $132.60 \mathrm{ppm}$, with mortality percentage $46.67 \pm 2.89$ and $50.00 \pm 0.00$, respectively. The LC50 doses showed pupation mortality percentage (31.21 and 46.67) and adult mortality percentage (36.90 and 63.33), respectively. As compared to control, the treated $2^{\text {nd }}$ larval instar with either $R$. communis or Z. officinalis essential oils showed significant decline in the fecundity of $M$. domestica females through significant decrease in the total eggs number as compared to control $(72.67 \%$ and 62.00\%) with Effective Repellency (ER\%) (51.34 and 58.48) and the Oviposition Activity (OAI) (-0.35 and -0.41$)$, respectively. The hatchability of eggs recorded significant reduction as compared to control $(86.38 \%$ and $73.66 \%$ ) for $R$. communis and $Z$. officinalis, respectively. The present study revealed toxic properties of the tested plant extracts of $R$. communis and $Z$. officinalis against $M$. domestica $\mathrm{L}$. and pave the way for its use as a measure of the eco-friendly housefly control.
\end{abstract}

Keywords: Musca Domestica L., Ricinus Communis, Zingiber Officinalis, Essential Oils, Larvicidal, Pupicidal, Adulticidal, Oviposition

\section{Introduction}

The housefly, Musca domestica (Linnaeus, 1758) (Diptera: Muscidae) considered one of the most hazardous pest on health in the environment transmitting many infectious diseases to human and livestock. (Cirillo, 2006; Barin et al., 2010; Farag et al., 2013; Hung et al., 2015). The larvae of the fly can also be myiasis-producing agents in human and animals leading to huge economic loses particularly in livestock industry (Stevens and Wallman, 2006; Singh and Singh, 2015).

The use of chemical insecticides for housefly control induced insect resistance, affected the environment through water and soil contamination and became toxic to vertebrates (Yoke and Sudderuddin, 1975; do Prado, 2003; Abbas et al., 2016; Kasai et al., 2017).

The use of plant extracts, as alternatives for housefly control could be very promising since these are ecofriendly, biodegradable as well as cost effective. A large number of plants have shown the remarkable insecticidal activities (Seo and Park, 2012; Singh and Kaur, 2016). Essential oils showed relatively non-toxic to fish, birds and mammals and easily biodegrade in the environment, turning them into good bio pesticides (Kumar et al., 2012). Many studies revealed satisfactory results from the use of several essential oils for the house fly $M$. domestica management (Abdel Halim and Morsy, 2005; Sinthusiri and Soonwera, 2013; Pinto et al., 2015). In addition, the synergistic action of essential oils with conventional chemical pesticide previously studied (Mansour and Mohamed, 2013).

The study designed to evaluate the larvicidal, pupicidal, adulticidal and ovicidal effect of lethal concentrations (LC50) of either R. communis or Z. officinalis essential oils against the housefly $M$. domestica $\mathrm{L}$.

\section{Materials and Methods}

\section{Collection of Flies}

Adults of M. domestica were collected in June 2015 from the garbage site of the Abu Arish area, (Eastern Jazan, $16^{\circ} 58^{\prime} \mathrm{N}$ to $42^{\circ} 47^{\prime} \mathrm{E}$ ), southern Saudi Arabia, by using a sweeping net and transported into a small cage to 
the Department of Biology, Faculty of Science, Jazan University for identification and reared in laboratory for four generations before experiment.

\section{Maintenance of Flies}

Adult flies maintained in cages $(30 \times 30 \times 30 \mathrm{~cm})$ and reared at $29 \pm 1^{\circ} \mathrm{C}$ and $65 \pm 5$ percentage $\mathrm{RH}$ and provided with granulated sugar petri dishes containing cotton pads soaked in milk powder dissolved in water $(10 \% \mathrm{w} / \mathrm{v})$ and jars $(500 \mathrm{ml})$ containing larval media for egg laying. The larval media consisted of yeast, dry milk powder, wheat bran and water according to the method previously described (Pavela, 2006). The jars removed from cages after 2-3 days when eggs visible and provided with wood dust for pupation and kept in separate cages for the fly emergence.

\section{Essential Oils}

The essential oils purchased from Sigma-Aldrich Company, Castor oil, $R$. communis of $99 \%$ purity, $0.961 \mathrm{~g} / \mathrm{ml}$ density and $n 20 / \mathrm{D} 1.478$ refractive index and Z. officinalis of $99 \%$ purity, $0.871 \mathrm{~g} / \mathrm{ml}$ density and $n 20 / \mathrm{D} 1.49$ refractive index. Four concentrations (4, 3, 2.5 and $1 \%$ ) prepared for the two essential oils dissolved in acetone and stored in glass bottles at $4{ }^{\circ} \mathrm{C}$ until used.

\section{Lethal Concentration (LC50) Bioassay}

The bioassay used the second instar larvae (3-daysold) hatched from the same egg batch. Larval treatment carried out in petri dishes according to method previously explained (Brady, 1966), where the interior of each petri dish treated with $1 \mathrm{ml}$ from each of the four aforementioned concentrations of the tested essential oils. Each experiment conducted in four replicates (20 larvae/replicate) along with the control group. After treatment, the larvae transferred to the rearing jar and the mortality assessed by touching each one larva with a paintbrush (no. 0) and those not responding considered dead. The LC50 for larval mortalities determined based on mortality data at $24 \mathrm{~h}$ (Hanan, 2013).

The calculated LC50 concentration values for either $R$. communis or $Z$. officinalis essential oils prepared using acetone solvent and stored in glass bottles at $4^{\circ} \mathrm{C}$ until they used for each one as a dose in the next bioassays.

\section{Pupicidal and Adulticidal Bioassays}

The larval mortality recorded as previously mentioned and the survived pupa used for the determination of the pupal mortality at 7 days. Then the survived adults used for the adulticidal bioassay, which determined following WHO susceptibility test guidelines (Sinthusiri and Soonwera, 2013).

\section{Oviposition Deterrent and Ovicidal Bioassay}

The oviposition deterrent and ovicidal bioassay according to the method of Morey and Khandagle
(2012). Ten of house fly females and males aged 4 days old introduced in a screened cage where two oviposition boxes lined with cotton pad, size $3 \times 10 \times 0.25 \mathrm{~cm}$. The first box filled with $1 \mathrm{ml}$ of $10 \% \mathrm{w} / \mathrm{v}$ milk solution and 1 $\mathrm{ml}$ of each test solution (LC50 of each essential oil), while the second box, which served as control, filled with only $1 \mathrm{ml}$ of $10 \% \mathrm{w} / \mathrm{v}$ milk. The boxes switched every day to avoid the position effects. The eggs laid into each box collected separately until no further eggs laid for at least $48 \mathrm{~h}$. Four replicates carried out with each test solution (LC50). The percentage of Effective Repellency (ER \%) and Oviposition Activity Index (OAI) were calculated using the next formula (Siriporn and Mayura, 2012):

$$
E R(\%)=N C-N T / N C \times 100
$$

Where:

$E R=$ Effective repellency

$N C=$ The total number of eggs in the control solution $N T=$ The total number of eggs in each test solution:

$$
O A I=N T-N C / N T+N C
$$

Where:

$N C=$ The total number of eggs in the control solution $N T=$ The total number of eggs in each test solution

The OAI ranges from -1.0 to +1.0 , with o indicating neutral response. The positive index values indicate that more eggs deposited in the test boxes than in the control boxes and that the test solutions attractive, on the other side, more eggs in the control boxes than on the test boxes results in negative index values and the test solution deterrent.

\section{Statistical Analysis}

The observed mortality corrected by Abbott's formula (Abbott, 1987). Data analyses were performed using a oneway ANOVA (Least Significant Difference (LSD) and significant differences were determined at $\mathrm{P}<0.05$. Statistical Package for Social Science "SPSS" for Windows software, Release 20.0 (SPSS, Chicago, IL) was used.

\section{Results}

Results of present study represented in Tables (1) and (2) declared the effect of both essential oils, $R$. communis and $Z$. officinalis as regard to larvicidal, pupicidal, adulticidal, total number of eggs and hatching percentage against $M$. domestica as compared with the analogous control. The assessment of $R$. Communis and $Z$. officinalis toxicity against $M$. domestica larvae revealed LC50 values $349.40 \mathrm{ppm}$ and $132.60 \mathrm{ppm}$, respectively, recording $46.67 \pm 2.89$ and $50.00 \pm 0.00$ mortality percentage that are significantly different at 0.05 level as compared with control value (11.67 \pm 2.89$)$. 
Table 1: Insecticidal effect of Ricinus communis and Zingiber officinalis essential oils against larvae, pupae and adult of housefly

\begin{tabular}{lllll}
\hline & Larvicidal activity & & & \\
Treatment & - & $\mathrm{LC}_{50}(\mathrm{ppm})$ & Pupicidal activity & Adulticidal activity \\
\hline Control & Mortality $(\%) \pm \mathrm{SD}$ & - & $15.14 \pm 3.53^{\mathrm{a}}$ & Mortality (\%) \pm SD \\
R. communis & $11.67 \pm 2.89^{\mathrm{a}}$ & 349.40 & $31.21 \pm 4.67^{\mathrm{b}}$ & $36.90 \pm 10.31^{\mathrm{b}}$ \\
Z. officinalis & $46.67 \pm 2.89^{\mathrm{b}}$ & 132.60 & $46.67 \pm 5.77^{\mathrm{c}}$ & $63.33 \pm 15.28^{\mathrm{c}}$ \\
\hline
\end{tabular}

Table 2: The total number of eggs laid, oviposition deterrent activity and hatching percent of Ricinus communis and Zingiber officinalis essential oils against housefly

\begin{tabular}{lllll}
\hline Treatment & Total number of eggs \pm SD & ER\% & OAI & Hatching\% \pm SD \\
\hline Control & $149.33 \pm 1.15^{\mathrm{a}}$ & - & - & $95.53 \pm 1.05^{\mathrm{a}}$ \\
R. communis & $72.67 \pm 3.06^{\mathrm{b}}$ & 51.34 & -0.35 & $86.38 \pm 5.82^{\mathrm{b}}$ \\
Z. officinalis & $62.00 \pm 2.65^{\mathrm{c}}$ & 58.48 & -0.41 & $73.66 \pm 1.44^{\mathrm{c}}$ \\
\hline
\end{tabular}

As regard to the survived pupae the recorded percentage mortality after 7 days (pupicidal activity) showed significant increase in mortality rate $(31.21 \% \pm 4.67)$ and $(46.67 \% \pm 5.77)$ for $R$. communis and $Z$. officinalis essential oils groups, respectively as compared to that of the control $(15.14 \% \pm 3.53)$. The adulticidal activities recorded in this study showed significant increase in mortality rate $(36.90 \% \pm 10.31)$ and $(63.33 \% \pm 15.28)$ for $R$. communis and $Z$. officinalis essential oils groups, respectively as compared to that of the control $(8.75 \% \pm 3.98)$ (Table 1$)$.

The effect of the LC50 of both essential oils on fecundity and eggs hatchability represented in Table (2). Data showed significant decrease in the total number of eggs laid in Z. officinalis group $(62.00 \pm 2.65)$ with ER $(58.48 \%)$ and OAI $(-0.41)$ as compared to that recorded number for $R$. communis group (72.67 \pm 3.06$)$ with ER (51.34\%) and OAI (-0.35) and both groups showed significant decrease as compared to the control group recorded number of eggs laid $(149.33 \pm 1.15)$.

Results in Table (2) showed that the hatching percentage of eggs in in Z. officinalis group (73.66 \pm 1.44) significantly decreased as compared to that recorded for $R$. communis group $(86.38 \pm 5.82)$ and both groups showed significant decrease as compared to that recorded for the control group $(95.53 \pm 1.05)$.

\section{Discussion}

The toxicity recorded in this study support different previous studies represented toxicity on larvae and adults as well as on fertility of plant origin essential oils against M. domestica (Pavela, 2008; Morey and Khandagle, 2012; Singh and Kaur, 2016; Walia et al., 2017). A previous study using $R$. communis extract recorded LC50 value of $353.4 \mathrm{ppm}$ after $72 \mathrm{~h}$ of exposure to the extract and reported that the extract contained the ribosome inactivating protein ricin (Alvarez Montes de Oca et al., 1996). A study using the chloroform leaves extract of $R$. communis predict larval and pupal mortality as well as reduction of pupations and non-emergence of adults of M. domestica as regard to the potent insecticidal component of $R$. communis (ricinine) confirming the effect on the housefly life cycle (Singh and Kaur, 2016) because ricinine has maximum solubility in chloroform (Rao, 1945). The gas chromatographic analysis with mass spectrometry (GC-MS) detected the main constituents of the $R$. communis essential oil, $\alpha$-thujone, 1,8-cineole, $\alpha$ pinene, camphor and camphene (Kadri et al., 2011; Zarai et al., 2012). The toxicity of these monoterpenoids against the housefly assessed (Kumar et al., 2012; 2013; Zhang et al., 2017). The mode of action of these constituents may elucidate the mechanism of the essential oil insecticidal activity, which had multiple targets. One of these targets is the effect on the nervous system receptors like $\gamma$-aminobutyric acid (GABA) receptors that predicted previously for the aforementioned monoterpenoids on the fly head (Tong and Coats, 2012). Another mechanism of the insecticidal activity for $R$. communis proposed due to inhibition of certain vital enzymatic pathways, in which flavonoids block hydroxylase enzyme by action of cytochrome- P450 which is involved in regulation of moulting process of insects (Upasani et al., 2003). In addition, flavonoids of $R$. communis reported to affect the insect ecdysone-20-monooxygenase, which is responsible for the synthesis of 20- hydroxyecdysone the precursor of insect growth hormone- ecdysone responsible for regulating the insects life cycle by initiating molting to grow into adults. Hence, the hindrance in the hormone synthesis affects the duration of prepupation period and adult emergence rates (Singh and Kaur, 2016).

Both essential oils significantly affect the oviposition deterrent and ovicidal activities as well as hatching rate but the advantage in toxicity recorded for $Z$. officinalis as compared to $R$. communis. The essential oil of $Z$. officinalis evaluated larvicidal activity and recorded LC50 value of 259 ppm against M. Domestica (Morey and Khandagle, 2012). Products isolated from $Z$. officinalis found to be effective as insect antifeedant and insect growth regulators (Agarwal et al., 2001). The essential oil of $Z$. officinalis caused significant larvicidal and repellency activity against $M$. domestica and found effective in repellent and oviposition deterrence assay (Morey and 
Khandagle, 2012; Krishna, 2013). A study recorded that $Z$. officinalis not only has a larvicidal action against $M$. domestica larvae but also affected the adult fecundity (Abdel, 2008). Data demonstrated that minimum pupal survival was shown in use of $Z$. officinalis essential oil which in line with previous study (Morey and Khandagle, 2012) where the essential oil of $Z$. officinalis exhibited significant bioactivities against $M$. domestica with larvicidal activity with Lethal Concentration (LC50) (137 ppm), repellency (84.9) and (98.1\%) oviposition deterrence both at $1 \%$ concentration. A study to evaluate Z. cussumunar essential oil as well as six other oils against $M$. domestica showed that the high concentration $(10 \%)$ of the essential oil revealed high percent effective repellency and showed the hatching rate decreased with oviposition deterrence (Sinthusiri and Soonwera, 2013). The analysis of $Z$. officinalis essential oil by GC-MS detected relatively large amounts of the monoterpenoids 1,8-cineole, linalool, borneol, alpha-terpineol, neral, geraniol, geranial, trans-dimethoxy citral and geranyl acetate (Gupta et al., 2011) which may related to its advantage of toxicity as compared to that recorded of $R$. communis against the fly (Kumar et al., 2013). In addition, these monoterpenoids existence in essential oil support the insect repellant activity (Showler, 2017).

\section{Conclusion}

The present study suggest that the essential oils of $Z$. officinalis and $R$. communiscan be effectively used as in controlling fly populations of $M$. domestica as the efficient, ecofriendly and economic alternative to synthetic insecticidal agents.

Data expressed as mean of three replicates One Way analysis performed between groups with LSD post hoc test with significance level 0.05 . Significance between different letters within the same column.

Data expressed as mean of three replicates One Way analysis performed between groups with LSD post hoc test with significance level 0.05 . Significance between different letters within column. ER\% is the percentage of effective repellency.OAI is the oviposition activity index. Hatching rate is the hatching percent. Hatching \% calculated by dividing the total hatch from the total number of eggs laid in each group.

\section{Acknowledgement}

The author would like to acknowledge the Department of Biology, Faculty of Science, Jazan University for the support in the laboratory work.

\section{Ethics}

The authors confirmed that this manuscript is an original work and do not contain any conflict of interest.

\section{References}

Abbas, N., R.M. Shah, S.A. Shad and F. Azher, 2016. Dominant fitness costs of resistance to fipronil in Musca domestica Linnaeus (Diptera: Muscidae). Vet Parasito., 226: 78-82.

DOI: $10.1016 /$ j.vetpar.2016.06.035

Abbott, W.S., 1987. A method of computing the effectiveness of an insecticide. J. Am. Mosq. Control Assoc., 3: 302-303. PMID: 3333059

Abdel, H.A., 2008. Efficacy of Zingiber officinale on third stage larvae and adult fecundity of Musca domestica and Anopheles pharoensis. J. Egypt Soc. Parasitol., 38: 385-392. PMID: 18853613

Abdel Halim, A.S. and T.A. Morsy, 2005. The insecticidal activity of Eucalyptus globulus oil on the development of Musca domestica third stage larvae. J. Egypt Soc. Parasito., 35: 631-636. PMID: 16083072

Agarwal, M., S. Walia, S. Dhingra and B.P. Khambay, 2001. Insect growth inhibition, antifeedant and antifungal activity of compounds isolated/derived from Zingiber officinale Roscoe (ginger) rhizomes. Pest Manag Sci., 57: 289-300. DOI: 10.1002/ps.263

Alvarez Montes de Oca, D.M., J.L. de la Fuente, O.L. Villarrubia Montes de Oca, J.C. Menéndez de San Pedro and E.O. Losada, 1996. The biological activity of Ricinus communis on the housefly (Musca domestica). Rev. Cuba Med. Trop., 48: 192-194. PMID: 9805050

Barin, A., F. Arabkhazaeli, S. Rahbari and S.A. Madani, 2010. The housefly, Musca domestica, as a possible mechanical vector of Newcastle disease virus in the laboratory and field. Med. Vet. Entomol., 24: 88-90. DOI: $10.1111 /$ j.1365-2915.2009.00859.x

Brady, U., 1966. A technique of continuous exposure for determining resistance of house flies to insecticides. J. Econ. Entomol., 59: 764-765. PMID: 5932271

Cirillo, V.J., 2006. Winged sponges": Houseflies as carriers of typhoid fever in 19th-and early 20th-century military camps. Perspect Biol. Med., 49: 52-63. DOI: $10.1353 / \mathrm{pbm} .2006 .0005$

do Prado, 2003. Controle das principais espécies de moscas em Jreas urbanas. Biolgico, S^o Paulo, 65: 95-97.

Farag, T.H., A.S. Faruque, Y. Wu, S.K. Das and A. Hossain et al., 2013. Housefly population density correlates with shigellosis among children in Mirzapur, Bangladesh: A time series analysis. PLoS Negl. Trop. Dis., 7: e2280-e2280.

DOI: 10.1371/journal.pntd.0002280

Gupta, S., P. Pandotra, G. Ram, R. An and A.P. Gupta et al., 2011. Composition of a monoterpenoid-rich essential oil from the rhizome of Zingiber officinale from north western Himalayas. Nat. Prod. Commun., 6: 93-96. PMID: 21366054 
Hanan, A., 2013. Evaluation of insecticidal activities of Mentha piperita and Lavandula angustifolia essential oils against house fly, Musca domestica L.(Diptera: Muscidae). J. Entomol. Nematol., 5: 50-54. DOI: $10.5897 /$ JEN2013.0073

Hung, K.Y., T.J. Michailides, J.G. Millar, A. Wayadande and A.C. Gerry, 2015. House Fly (Musca domestica L.) Attraction to Insect Honeydew. PloS one. DOI: 10.1371 journal.pone.0124746

Kadri, A., N. Gharsallah, M. Damak and R. Gdoura, 2011. Chemical composition and in vitro antioxidant properties of essential oil of Ricinus communis L. J. Med. Plant. Res., 5: 1466-1470.

Kasai, S., H. Sun and J. Scott, 2017. Diversity of knockdown resistance alleles in a single house fly population facilitates adaptation to pyrethroid insecticides. Insect Mol. Biol., 26: 13-24.

DOI: $10.1111 / \mathrm{imb} .12267$

Krishna, P.R., 2013. Bioactivity of some medicinal plants on insect pest/vector. Ph.D. Thesis. Tibrewala University, Rajasthan, India.

Kumar, P., S. Mishra, A. Malik and S. Satya, 2013. Housefly (Musca domestica L.) control potential of Cymbopogon citratus Stapf.(Poales: Poaceae) essential oil and monoterpenes (citral and 1, 8-cineole). Parasitol. Res., 112: 69-76.

DOI: 10.1007/s00436-012-3105-5

Kumar, P., S. Mishra, A. Malik and S. Satya, 2012. Insecticidal evaluation of essential oils of Citrus sinensis L. (Myrtales: Myrtaceae) against housefly, Musca domestica La.(Diptera: Muscidae). Parasitol Res., 110: 1929-1936.

DOI: 10.1007/s00436-011-2719-3

Mansour, S.A. and R.I. Mohamed, 2013. Insecticidal properties and chemical composition of Conyza Aegyptiaca (L.) oil: Studies on two dipterous insect pests. Open Toxicol J., 5: 1-7. DOI: $10.2174 / 1875414701305010001$

Morey, R.A. and A.J. Khandagle, 2012. Bioefficacy of essential oils of medicinal plants against housefly, Musca domestica L. Parasitology Res., 111: 1799-1805.

DOI: $10.1007 / \mathrm{s} 00436-012-3027-2$

Pavela, R., 2006. Insecticidal activity of essential oils against cabbage aphid Brevicoryne brassicae. J. Essent Oil Bear Pl., 9: 99-106. DOI: $10.1080 / 0972060 X .2006 .10643479$

Pavela, R., 2008. Insecticidal properties of several essential oils on the house fly (Musca domestica L.). Phytother Res., 22: 274-278. DOI: 10.1002/ptr.2300

Pinto, Z.T., F.F. SUnchez, A.R. dos Santos, A.C. Amaral and J.L. Ferreira et al., 2015. Chemical composition and insecticidal activity of Cymbopogon citratus essential oil from Cuba and Brazil against housefly. Rev. Bras Parasitol Vet., 24: 36-44.

DOI: $10.1590 / \mathrm{S} 1984-29612015006$
Rao, N.V.S., 1945. A note on the chemical composition of castor leaves. Proc. Indian Acad. Sci., 21: 123-125. DOI: $1007 / \mathrm{BF} 03051280$

Seo, S.M. and I.K. Park, 2012. Larvicidal activity of medicinal plant extracts and lignan identified in Phryma leptostachya var. asiatica roots against housefly (Musca domestica L.). Parasitol Res., 110: 1849-1853. DOI: 10.1007/s00436-011-2709-5

Showler, A.T., 2017. Botanically based repellent and insecticidal effects against horn flies and stable flies (Diptera: Muscidae). J. Integr Pest Manag., 8: 1-15. DOI: $10.1093 / \mathrm{jipm} / \mathrm{pmx} 010$

Singh, A. and J. Kaur, 2016. Toxicity of leaf extracts of ricinus communis L.(Euphorbiaceace) against the third instar larvae of Musca domestica L. (Diptera: Muscidae). Am. J. BioScience, 4: 5-10. DOI: $10.11648 /$ j.ajbio.s.2016040301.12

Singh, A. and Z. Singh, 2015. Incidence of myiasis among humans-a review. Parasitol Res., 114: 3183-3199. DOI: 10.1007/s00436-015-4620-y

Sinthusiri, J. and M. Soonwera, 2013. Efficacy of herbal essential oils as insecticides against the housefly, Musca domestica L. Southeast Asian J. Trop Med. Public Health, 44: 188-196. PMID: 23691628

Siriporn, P. and S. Mayura, 2012. The effects of herbal essential oils on the oviposition-deterrent and ovicidal activities of Aedes aegypti (Linn.), Anopheles dirus (Peyton and Harrison) and Culex quinquefasciatus (Say). Trop Biomed., 29: 138-150. PMID: 22543614

Stevens, J.R. and J.F. Wallman, 2006. The evolution of myiasis in humans and other animals in the old and new worlds (part I): Phylogenetic analyses. Trends Parasitol., 22: 129-136. DOI: 10.1016/j.pt.2006.01.008

Tong, F. and J.R. Coats, 2012. Quantitative structureactivity relationships of monoterpenoid binding activities to the housefly GABA receptor. Pest Manag. Sci., 68: 1122-1129. DOI: 10.1002/ps.3280

Upasani, S.M., H.M. Kotkar, P.S. Mendki and V.L. Maheshwari, 2003. Partial characterization and insecticidal properties of Ricinus communis $\mathrm{L}$ foliage flavonoids. Pest Manag. Sci., 59: 1349-1354 . DOI: $10.1002 /$ ps.767

Walia, S., S. Saha, V. Tripathi and K.K. Sharma, 2017. Phytochemical biopesticides: Some recent developments. Phytochem Rev., 16: 989-1007. DOI: $10.1007 / \mathrm{s} 11101-017-9512-6$

Yoke, O.P. and K.I. Sudderuddin, 1975. Toxicological studies of four insecticides against Musca domestica L. Southeast Asian J. Trop. Med. Public Health., 6: 525-531. PMID: 818717 
Zarai, Z., I.B. Chobba, R.B. Mansour, A. Békir and N. Gharsallah et al., 2012. Essential oil of the leaves of Ricinus communis L.: in vitro cytotoxicity and antimicrobial properties. Lipids Health Dis., 11: 102-102. DOI: $10.1186 / 1476-511 X-11-102$
Zhang, Z., Y. Xie, Y. Wang, Z. Lin and L. Wang et al., 2017. Toxicities of monoterpenes against housefly, Musca domestica L. (Diptera: Muscidae). Environ. Sci. Pollut Res. Int., 24: 24708-24713.

DOI: $10.1007 / \mathrm{s} 11356-017-0219-4$ 